\title{
Levels and trends of synthetic musks in marine bivalves from French coastal areas
}

\author{
Aminot Yann ${ }^{1,}{ }^{*}$, Munschy Catherine ${ }^{1}$, Héas-Moisan Karine ${ }^{1}$, Pollono Charles ${ }^{1}$, Tixier Celine ${ }^{1}$
}

1 IFREMER (Institut Français de Recherche pour l'Exploitation de la Mer), Laboratory of

Biogeochemistry of Organic Contaminants, Rue de l'lle d'Yeu, BP 21105, Nantes Cedex 3, 44311,

France

*Corresponding author : Yann Aminot, email address : yann.aminot@ifremer.fr

\begin{abstract}
:
The levels and trends of four bioaccumulative synthetic musks (galaxolide - HHCB, tonalide - AHTN, musk xylene - MX and musk ketone - MK) were investigated in filter-feeding bivalves collected yearly since 2010 at sites of contrasted pressure along the French coasts. Quantification rates were high for all 4 compounds (85-99\%), indicating their geographical and temporal extensive occurrence in the French coastal environment. The polycyclic musks HHCB and AHTN prevailed, with median concentrations of $2.27 \mathrm{ng} \mathrm{g}-1 \mathrm{dw}$ and of $0.724 \mathrm{ng} \mathrm{g}-1 \mathrm{dw}$, whilst nitromusks were found 1 to 2 orders of magnitude lower. These levels were in the high range of those encountered for various other CEC families at the same sites and comparable to those from other locations on European coasts. Unlike for the other musks, the accumulation of HHCB was evidenced to be species-specific, with significantly lower levels found in oysters in comparison with mussels, possibly suggesting a higher metabolization in oysters. Geographical differences in musk distribution highlighted the sites under strong anthropogenic pressures and these differences were found to be consistent between years. The HHCB/AHTN ratio proved to be discriminant to explain the relative occurrence of polycyclic musks. The 8-year time series showed that only the nowbanned compound MX displayed a significant decrease in most sites, whilst stable concentrations of the other musks suggested consistency in their usage over the last decade. These results provide reference data for future studies of the occurrence of personal care products on European coasts.
\end{abstract}

\section{Highlights}

- Investigation of synthetic musks in bivalves from French coasts in 2010-2019. Widespread occurrence of HHCB, AHTN, musk xylene and ketone. Species-specific accumulation of HHCB, potentially related to metabolization. Levels reflect urban pressure, notably in the Seine Bay. Significantly decreasing temporal trend for musk xylene only.

Keywords : coastal marine environment, bioaccumulation, shellfish, Personal Care Products (PCPs), Galaxolide, Tonalide 


\section{1. Introduction}

40 Synthetic musks are extensively used as fragrance additives in a wide range of scented

41 consumer goods, such as personal care (perfumes, soaps, deodorants, shampoo, etc.) and

42 household products (air fresheners, cleaning agents, detergents, etc.). Among the predominant

43 compounds in these products are polycyclic musks (galaxolide - HHCB and tonalide -

44 AHTN), macrocyclic musks and nitromusks (musk ketone - MK and musk xylene - MX)

45 (Nakata et al., 2015; Reiner and Kannan, 2006; Sanchez-Prado et al., 2011). Although in 2004

$4695 \%$ of the European market for all polycyclic and nitromusks was composed, in decreasing

47 tonnage, of HHCB, AHTN, MK and MX (OSPAR, 2008), the previously cited studies have

48 reported the growing use of the more degradable macrocyclic musks and the lower prevalence

49 of nitromusks in consumer products in the last 10-15 years. Very persistent, very

50 bioaccumulative (vPvB) and toxic, MX has been banned under the European REACH 
regulation (Registration, Evaluation, Authorization and Restriction of Chemical substances) since 2011 (European Commission, 2011). This compound has also been included in the List of Chemicals for Priority Action of the Convention for the Protection of the Marine Environment of the North-East Atlantic (OSPAR Convention) since 1998. Recent data have established that the polycyclic musks HHCB and AHTN are produced or imported between 1,000 and 10,000 tons per year in the EU and the nitro-musk ketone (MK) between 100 and 1,000 $\mathrm{t}^{-1}$ (ECHA, 2020). HHCB and AHTN are recognized as priority substances by the Norman network (https://www.norman-network.net/?q=node/19) and HHCB belongs to the Howard and Muir's list of high-priority pollutants regarding persistence and bioaccumulation potential (Howard and Muir, 2010).

Reflecting their use, synthetic musks enter the aquatic environment mainly via effluents from waste water treatment plants (WWTPs, Homem et al., 2015), a different pathway to most persistent organic pollutants (POPs, Melymuk et al., 2014). Synthetic musks have subsequently been found in coastal waters and sediments receiving anthropogenic inputs (Aminot et al., 2019; Lee et al., 2014; Sumner et al., 2010). Further volatilization (McDonough et al., 2016) and direct release to ambient air from urban areas (Weinberg et al., 2011; Wong et al., 2019) cause atmospheric contamination. If the potential for long-range transport is debated (Wong et al., 2019 and references herein), synthetic musks have been detected in polar environments (Xie et al., 2007) and in alpine locations (Ferrario et al., 2017), suggesting dry/wet deposition as a possible secondary source of oceanic contamination.

Due to their lipophilic character (log Kow 4-6), these substances tend to accumulate in marine biota (Liu et al., 2020), and bivalves in particular (Nakata et al., 2012; Picot Groz et al., 2014).

Based on a rather low reported (eco)toxicity of most synthetic musks, several evaluations have assumed that such compounds pose no risk to the marine environment (OSPAR, 2019) 
despite their relatively high concentration levels (Casatta et al., 2015; Nakata et al., 2012). The recent global concerns on endocrine disruption have prompted a new evaluation of HHCB and AHTN within the European REACH framework as of 2020, whilst the possibility for a systematic underestimation of their toxicity in laboratory conditions in vivo due to inadequate experimental design for testing semi-volatile compounds was raised (Tumová et al., 2019). Regardless of their toxicity, the authors share the opinion that the persistence of contaminants in the environment is, by itself, a major cause of concern warranting further research (Cousins et al., 2019).

Monitoring of bioaccumulative contaminants using filter-feeding shellfish as sentinel species has long been a technique of choice for the determination of the levels and trends of POPs in the marine environment, in particular within large scale "Mussel watch" programs operated/conducted worldwide (Farrington et al., 2016). More recently, the inclusion of Contaminants of Emerging Concern (CECs) alongside the well-established POPs allowed the environmental evaluation in coastal ecosystems of various compounds such as non-PBDE flame retardants (Isobe et al., 2012; Munschy et al., 2015), alkylphenols (Dodder et al., 2014), PFASs (Munschy et al., 2019), or personal care products (Nakata et al., 2012). Regarding synthetic musks, although a number of studies reported concentrations of synthetic musks in coastal ecosystems, extended evaluations of spatial distribution and recent evaluations of their temporal variabilities in the marine environment arelacking. In light of the above, this study aims to investigate the levels, geographical distribution and inter-annual trends of 4 selected synthetic musks in shellfish collected between 2010 and 2019 at 21 sites of contrasted anthropogenic pressure along the French coastlines.

\section{Materials and methods}

\subsection{Chemicals and reagents}


100 All chemicals were carefully-selected to satisfy trace analysis requirements. Picograde ${ }^{\circledR}$

101 solvents (dichloromethane - DCM, n-hexane, isooctane, methanol, ethyl acetate) were 102 purchased from Promochem (Germany) or LGC Standards (France). Bio-Bead S-X3 103 polystyrene gel beads (200-400 Mesh) were supplied by Bio-Rad Laboratories Inc. (USA). 104 Silica gel (100-200 Mesh), aluminium oxide (90 standardized), Florisil (60-200 Mesh) were 105 supplied respectively by Sigma Aldrich (Germany), Merck (Germany) and Fluka (Germany).

106 Musk standards were purchased from LGC Standards (France): 1,3,4,7,8-hexahydro107 4,6,6,7,8,8-hexamethylcyclopenta- $(\gamma)$-2-benzopyran (HHCB, 51\% purity and 73\% purity in 108 2019); 4-aceto-3,5-dimethyl-2,6-dinitrotert-butylbenzene (MK, 98\%); 7-acetyl-1,1,3,4,4,6109 hexamethyl-1,2,3,4-tetrahydronaphthalene (AHTN, 98.5\%) and 2,4,6 -trinitro-1,3-dimethyl-5110 tert-butylbenzene (MX, 99.5\%). Standard purity was accounted for in the preparation of the 111 parent solutions. Regarding HHCB low purity, a higher grade (Dr. Ehrenstorfer, $73 \%$ ) was 112 used in 2019. Consistent response coefficients and accurate measurements of our in-house QC 113 material confirmed the suitability of all HHCB standards used. Deuterated-musk xylene (MX114 d15, chemical purity 96.8\% - LGC Standards, France) was used as internal standard and d10115 Phenanthrene (Phe-d10, 98\% - CIL, USA) or $d 9$-musk xylene (MX-d9, 98\% - CIL, USA) 116 were used as an injection standard. Deuterated-AHTN (AHTN-d3, LGC Standards, France) 117 was tested for use as a potential internal standard but $\mathrm{D}-\mathrm{H}$ exchange occurring during the 118 preparation protocol caused an unacceptable increase of AHTN levels in procedural blanks, in 119 agreement with previous reports (Bester, 2009).

\subsection{Sampling strategy}

121 The mussel (Mytilus spp) and oyster (Crassostrea gigas) samples used for our study were 122 collected annually in autumn (out of spawning season) in 2010 and from 2013 to 2019 at the 123 same selected locations in the English Channel, Atlantic and along Mediterranean coasts, as 
124 shown in Figure 1. These locations cover main estuaries and deltas (Seine, Loire, Gironde,

125 Rhône), together with smaller tributaries and various locations away from direct sources.

126 The shellfish were collected and handled in accordance with international guidelines for the

127 monitoring of contaminants in biota (OSPAR, 2018), as previously described (Munschy et al.,

128 2019). Briefly, all samples were collected in the same manner and at the same time of year

129 (from late November to early December); each individual had spent at least 6 months in situ

130 beforehand. Each composite sample consisted of at least $50 \pm 5$ mussels of similar size (30-

$13160 \mathrm{~mm}$ shell length) or $10 \pm 1$ oysters $(90-140 \mathrm{~mm}$ shell length). All samples were

132 systematically depurated in settled water from the site for $24 \mathrm{~h}$, shelled, homogenized (whole

133 soft body) and stored at $-20^{\circ} \mathrm{C}$ prior to freeze-drying (dry weights provided in Table S1). The

134 dried samples were stored in a cool, dry, dark place until further analysis.

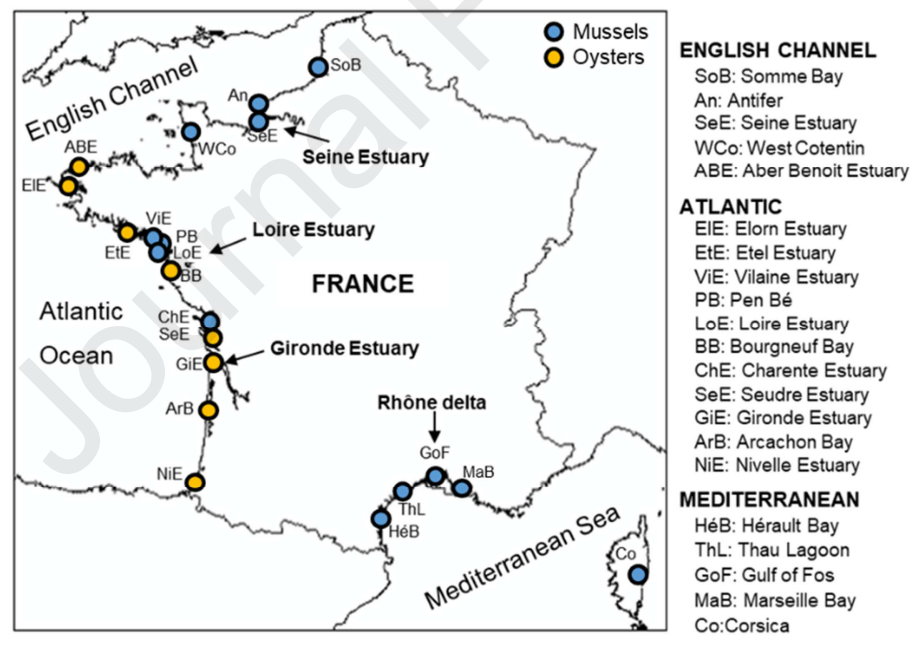

136 Figure 1. Sampling sites for bivalves collected in 2010 and from 2013 to 2019 from the

137 English Channel, Atlantic and Mediterranean coasts

\subsection{Sample preparation and analysis}

139 The entire sample preparation and subsequent analyses were performed in clean laboratories,

140 under a low-dust atmosphere and positive pressure (ISO 8 class according to NF EN ISO 
141 14644). Between 2 and 5 grams of freeze-dried bivalve sample were spiked with the internal

142 standard MX-d15 and extracted by Accelerated Solvent Extraction (ASE, Dionex) using

$143 \mathrm{DCM} / n$-hexane (50:50, v:v). The extracts were cleaned on a gel permeation chromatography

144 glass column $(460 \mathrm{~mm} \times 26 \mathrm{~mm})$ filled with styrene-divinylbenzene $(65 \mathrm{~g}$ of Bio-beads SX3)

145 and eluted with DCM (185 mL first discarded, followed by $65 \mathrm{~mL}$ of the analyte elution

146 fraction). Purification was further performed on both florisil and silica/alumina columns

147 eluted respectively with $n$-hexane/ethyl acetate (95:5, v:v) and $n$-hexane/DCM (60:40, v:v).

148 After concentration in isooctane, the extracts were spiked with the injection standards Phe-

$149 \mathrm{~d} 10$ (samples from 2010-2017) or the more-closely related MX-d9 (2018-2019).

150 The instrumental analyses for samples from 2010 to 2016 were performed on an Agilent 7890

151 gas chromatograph coupled to an Agilent 5975 mass spectrometer (GC/MS) equipped with an

152 EI and NCI sources, and from 2017 onwards using a Agilent A7890 coupled to a Waters

153 Xevo TQ-S micro triple quadrupole mass spectrometer (GC-MS/MS) equipped with an

154 APGC source (APCI). The configuration was as follows: HHCB EI or APGC, AHTN EI or

155 APGC, MX NCI, MK NCI or APGC. Ions were monitored by single ion monitoring (single

156 MS) or multiple reaction monitoring (tandem MS). The GC was fitted with a DB-5 MS

157 capillary column $(40 \mathrm{~m} \times 0.18 \mathrm{~mm} \times 0.18 \mu \mathrm{m})$ with helium as the carrier gas $\left(0.8 \mathrm{~mL} \mathrm{~min}^{-1}\right.$ in

158 GC-MS and $1.5 \mathrm{~mL} \mathrm{~min}^{-1}$ in GC-MS/MS). Musks were separated in a $42 \mathrm{~min}$ (GC/MS) or 34

$159 \min (\mathrm{GC}-\mathrm{MS} / \mathrm{MS})$ temperature gradient from $110{ }^{\circ} \mathrm{C}$ to $320{ }^{\circ} \mathrm{C}$, with an inlet temperature of

$160280{ }^{\circ} \mathrm{C}$. Relative response factors of target analytes relative to internal standard (MX-d15)

161 were calculated from a 7-point calibration curve for quantification. MX-d15 recovery was

162 calculated against the injection standard (Phe-d10 or MX-d9).

163 QA/QC is provided in supplementary information (QA/QC section, Fig S1 and Fig S2).

\subsection{Statistical analysis}


165 Statistical analyses were performed using Addinsoft XLStat software. Spearman rank

166

167

168

169

170

171

172

173

174

175

176

177

178

179

180

181

182

correlations were applied (Spearman " $\rho$ " coefficient). The non-parametric Mann-Whitney test was used for comparison of two independent samples, with a significance level of 0.01 . The significance of the temporal trend was assessed using the non-parametric Mann-Kendall statistical method, which assesses ranks across samples. Concentrations < LOQs (less than $15 \%$ of the samples, see detection frequencies in 3.1) were ignored in correlation analyses, counted as zero in distribution profiles and given a value of $\mathrm{LOQ} / 2$ in temporal trend analysis.

\section{Results and discussion}

\subsection{Levels and profiles of synthetic musks}

Among the 125 samples analysed over the 9 year study, AHTN was quantified in $99 \%$ (annual min-max 95-100\%), MK in 92\% (77-100\%), MX in 89\% (64-100) and HHCB in 85\% (73-100\%) of the samples. The highest median concentrations were found for the polycyclic musks HHCB at $2.27 \mathrm{ng} \mathrm{g}^{-1} \mathrm{dw}\left(\min 0.131-\max 54.5 \mathrm{ng} \mathrm{g}^{-1} \mathrm{dw}\right)$ and AHTN at $0.724 \mathrm{ng} \mathrm{g}^{-1}$ $\mathrm{dw}\left(\min 0.146-\max 9.30 \mathrm{ng} \mathrm{g}^{-1} \mathrm{dw}\right.$ ). The nitro-aromatic musks MX and MK were found at median concentrations of $0.032 \mathrm{ng} \mathrm{g}^{-1} \mathrm{dw}\left(\min 0.009-\max 0.167 \mathrm{ng} \mathrm{g}^{-1} \mathrm{dw}\right)$ and $0.066 \mathrm{ng} \mathrm{g}^{-1}$ $\mathrm{dw}\left(\min 0.006-\max 1.47 \mathrm{ng} \mathrm{g}^{-1} \mathrm{dw}\right.$ ), respectively. These levels are consistent with their usage in Europe, as MX use is now banned and MK is in a lower production/import tonnage band (100-1 000 for MK vs 1 000-10 $000 \mathrm{t} \mathrm{y}^{-1}$ for HHCB and AHTN, ECHA, 2020).

In comparison with other hydrophobic contaminants also analysed in the same samples, synthetic musks were found to be the most abundant, with concentrations decreasing as follows: in the $\mathrm{ng} \mathrm{g}^{-1} \mathrm{dw}$ : polycyclic musks; in the hundreds of $\mathrm{pg} \mathrm{g}^{-1} \mathrm{dw}$ : perfluorocarboxylic acids $\left(\sum \mathrm{C}_{9}-\mathrm{C}_{14}\right.$ PFCAs $)>$ perfluorooctane sulfonate $(\mathrm{PFOS}) \sim$ polybrominated diphenyl ethers ( $\sum 8$ OSPAR PBDE congeners) > hexabromocyclododecane (HBCDD); in the tens of $\operatorname{pg~g}^{-1}$ : nitromusks and alternative brominated flame retardants (BTBPE, DBDPE) (for further 
details, refer to (Munschy et al., 2019, 2015, 2013). Similar rankings between contaminant

190 families have been reported worldwide; however, co-analysis of synthetic musks and other

191 contaminants in bivalve biomonitoring programme has seldom been reported. In the Asia-

192 Pacific region, synthetic musk levels were also one to two orders of magnitude higher than

193 PBDEs (Nakata et al., 2012) and in clams of an Italian lagoon under influence of the Po

194 River, AHTN concentrations were $~ 100$ times higher than PBDEs and $~ 10-100$ times higher

195 than HBCDDs (Casatta et al., 2015). In light of these rankings, synthetic musks in the marine environment should deserve a wider attention from the marine research community and in marine biomonitoring programs.

All sites and years confounded, all compounds (but HHCB with MX) were significantly correlated ( $\rho$ between 0.42 and 0.87); however, the correlation appears altered by the high values found in the Seine Estuary and Bay (details on the correlations are given in Table S2).

201 After exclusion of these strong outliers, no correlation was found between HHCB and any of the other musks ( $\rho$ between 0.11 and 0.24 ) when both species were considered together. However, when considered separately and without outliers, HHCB concentrations significantly correlated with AHTN and MK ones in both mussels (AHTN $\rho=0.59, \mathrm{n}=62$; MK $\rho=0.47, n=56$ ) and oysters (AHTN $\rho=0.64, n=28$; MK $\rho=0.54, n=28)$. AHTN, MX and MK were significantly correlated regardless of the bivalve subset ( $\rho$ 0.37-0.88), with the strongest correlation observed between AHTN and MK $(\rho 0.75-0.88, \mathrm{p}<0.01)$. As HHCB, AHTN and MK share a common wastewater-derived source (Homem et al., 2015), the weaker correlations with HHCB would suggest a dissimilarity in its environmental behaviour (such as

210 persistence and bioaccumulation). However, the paucity of comparable data on the 211 environmental degradation of musks and the somewhat variable bioaccumulation factors reported in the literature prevent further examination of this hypothesis. 
213 In abiotic media from various locations worldwide, HHCB and AHTN are found to co-vary.

214 Examples where their concentrations are strongly correlated have been observed in water and 215 sediment samples from the Songhua River, China (Lu et al., 2015), in sewage and surface 216 water samples from South Korea (Lee et al., 2010) and in coastal waters from southern Spain 217 (Pintado-Herrera et al., 2020). These studies highlight similar sources and behaviours for 218 these two SMs. Further, these observations suggest that the lack of correlation we observed 219 when mussels and oysters were considered together does not reflect geographical 220 peculiarities, but rather points towards a species-specific pattern. The musk distribution profiles (Figure 2) were indeed significantly distinct in the 8 sites sampled for oysters, with HHCB composing $18-35 \%$ of the profiles, while the 13 mussel-monitored sites had a much higher contribution of HHCB (64-92\%, except for one site at 36\%). When considering the concentrations measured at all sites and years for mussels and oysters separately (Figure S3), no significant differences in concentrations between species were observed for AHTN, MX and MK, in contrast to HHCB concentrations in oysters, significantly lower (p-value < $0.0001)$ than in mussels by an average factor of 5. This difference cannot be attributed to a specific matrix effect as good recoveries were obtained for both matrices on spiked controls 229 (see Fig S2). With comparable hydrophobicity (log $\mathrm{K}_{\mathrm{ow}}$ of 5.3 and 5.4, (EU, 2008a, 2008b), HHCB lower bioaccumulation in oysters compared with AHTN could relate to partial metabolism of HHCB in this species. Supporting their use as bioindicators, the metabolic 232 capacities of bivalves are generally considered to be low (Beyer et al., 2017), and such 233 biotransformation of HHCB by bivalves has not been reported in the literature. Species234 specific accumulation patterns of musks have been observed in various freshwater fish species, with more pronounced differences in HHCB accumulation compared with AHTN 236 (Gatermann et al., 2002). The authors attributed this result to varying metabolic capacities of 237 freshwater fish, in conjunction with the inherent stronger susceptibility of HHCB to undergo 
238 metabolization. In another study on a marine fish of higher trophic level (sea bass -

239 Dicentrarchus labrax), HHCB was also found to be actively metabolised (Fernandes et al.,

240 2013). The presence of a stable transformation product of HHCB, HHCB-lactone, has been

241 reported in biota (Lange et al., 2015; Trabalón et al., 2015), but its use as a tracer for

242 metabolism warrants further research as it can also originate in the environment by chemical,

243 photochemical and/or microbiological processes. In marine bivalves, similar bioaccumulation

244 factors for HHCB and AHTN have been reported for Lokan clams (Polymesoda expansa) and

245 Asian green mussels (Perna viridis) (Bayen et al., 2019). HHCB and AHTN were also found

246 to correlate regardless of the species (Perna viridis, Mytilus edulis.) in the Asia-Pacific mussel

247 watch (Nakata et al., 2012). Further research is needed to unambiguously attribute our

248 observations to oyster-specific metabolism, and definitely exclude peculiar contamination

249 profiles of certain bivalve collection sites.

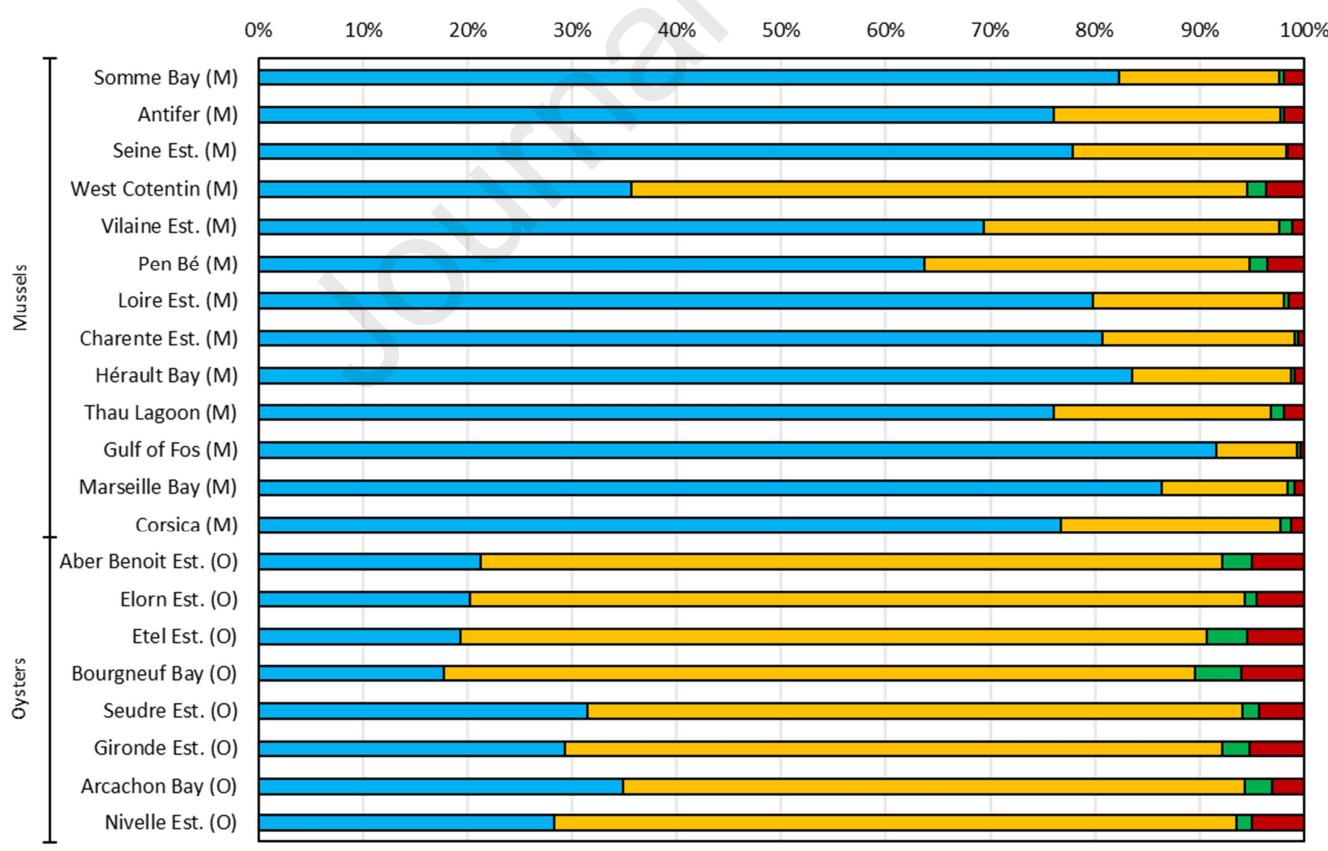


Figure 2. Relative distribution of the musk concentrations in mussels (M) and oysters (O)

252 collected on the French coastlines in 2010-2019, using the site median concentrations $(n=4$

253 to 8, depending on the site). Non-detects were attributed the value LOQ/2.

\subsection{Comparison with worldwide levels}

255 The musk contamination levels observed in this study were compared to those reported in the 256 literature in filter-feeding bivalves from other countries (Table 1). These should be considered 257 with caution due to differences in data calculation methods (dry, wet or lipid weight 258 calculation), or lack of information on sample preparation. In the absence of a depuration 259 phase after sampling, ingested particles could incorrectly contribute to body-burden 260 concentrations (Booij et al., 2002). Moreover, results are rarely associated with sampling 261 periods, despite the significant influence of bivalve sexual maturity (spawning season and 262 lipid content) on contamination by lipophilic organic contaminants. Considering the limited 263 amount of data available for synthetic musks in marine bivalves, concentrations reported prior 264 to our period of study were also included, but comparisons should be made with extra care 265 when dealing with contaminants known or expected to show temporal variations. The levels 266 we reported are similar to those reported in Europe, with a predominance of the polycyclic 267 musks HHCB and AHTN over the nitro-musks. The maximum levels observed are also 268 comparable to those reported for three sites located at the mouth of different rivers in southern 269 Europe in Italy, Spain, and Portugal (Cunha et al., 2015; Saraiva et al., 2016) or on touristic areas of South Portugal (Castro et al., 2018; Picot Groz et al., 2014). In Northern Europe,

271 Rüdel et al. (2006) performed a retrospective analysis of mussel samples from the German

272 Environmental Specimen Bank (from 1986 to 2000). The levels determined for the North Sea, 273 ranging from $0.5-1.7 \mathrm{ng} \mathrm{g}^{-1} \mathrm{ww}$ for HHCB and $0.4-2.5 \mathrm{ng} \mathrm{g}^{-1} \mathrm{ww}$ for AHTN, compare to 274 those obtained in most of our samples, while far lower levels were reported in the Baltic Sea. 275 Somewhat higher results were reported outside of Europe, in Asia, Canada or along the 
Pacific coast of the United States, but differences in fragrance uses and practises cannot be

277 excluded. In the late 1990's, significantly different levels of polycyclic vs nitro-musks between Canadian and European biota were attributed to the highest use of nitro-musks in products from North America compared with Western Europe (Gatermann et al., 1999). In Korea, although musk consumption patterns differed (in 2006: HHCB, 88 t/year; MK, 20 t/year; MX, 0.5 t/year; AHTN, below 0.1 t/year), bivalve contamination profiles remain comparable to those found elsewhere, a result attributable to the higher lipophilicity of AHTN and the potential contribution of global atmospheric sources (Lee et al., 2010, 2014). In between Asian countries, the bivalve contamination profiles were also found to differ, with high AHTN levels (relative to HHCB's) found in the 7 studied Japanese Mytilus edulis samples in comparison to those found in that same species and in Perna viridis in other Asian countries (Nakata et al., 2012). All of the studies, however, show high discrepancies in the contamination levels, with the influence of local point sources. On the Pacific coast of the USA, Nakata et al. (2012) observed high HHCB contamination levels (1600 to $2200 \mathrm{ng} \mathrm{g}^{-1}$ lw) in San Francisco Bay (SF $\sim 9.7$ million inhab.) while for all the other stations on the west coast, the levels were lower than $200 \mathrm{ng} \mathrm{g}^{-1} \mathrm{lw}$. Similar contrasted observations were made for the various sites located in Hong Kong Bay (HK 7.4 million inhab.), with the highest levels found near the discharge point of treated wastewaters. The level of contamination appears related to the size of the wastewater catchment area, and to the distance-driven dilution between the sampling point and the urbanised contamination sources.

Table 1. Musk concentrations (minimum - maximum and/or median/mean ( $\pm \mathrm{sd})$ in $\mathrm{ng} \mathrm{g}^{-1} \mathrm{dw}$ ) in marine filter-feeding bivalves from various coastal locations (including this study, concentrations <LOQ not considered). nd: not detected; na: not analysed. 
Year Species

Concentration (min - max / median or mean)

(ng g ${ }^{-1}$ dry weight*, wet weight ${ }^{\#}$ or lipid weight)

\section{Reference}

$\begin{array}{llll}\text { HHCB AHTN MX } & \text { MK }\end{array}$

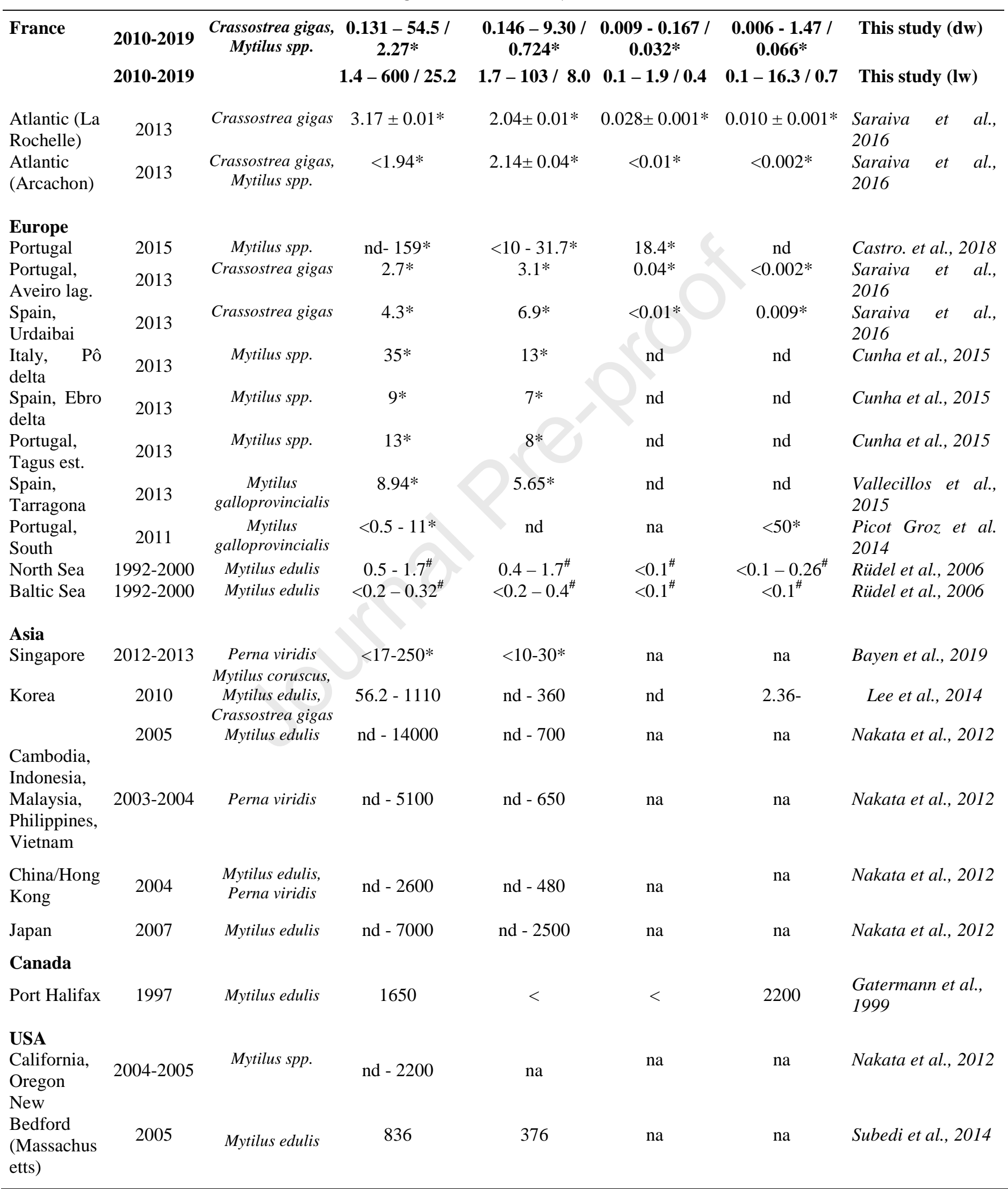




\subsection{Geographical distribution of concentrations}

302

303

304

HHCB, AHTN and MK highest levels were consistently found in mussels from the Seine estuary and further along in the Bay, with median values of $20.5,5.38$ and $0.420 \mathrm{ng} \mathrm{g}^{-1} \mathrm{dw}$, respectively (Figure 3). This could obviously be attributed to the high anthropogenic pressure in the Seine estuary catchment area, draining effluents from an estimated 17 million inhabitants (around a quarter of the French population) and known to be a highly-impacted estuary by various contaminants (Munschy et al., 2015; Tappin and Millward, 2015). In relation with the aforementioned species-specific bioaccumulation, the geographical differences in HHCB concentrations were considered for mussels and oysters separately. Among mussel sites, the Loire estuary and the Mediterranean sites of the Gulf of Fos, the Hérault, and Marseille Bays showed high median concentrations, between 3.82 and $6.52 \mathrm{ng} \mathrm{\textrm {g } ^ { - }}$ ${ }^{1} \mathrm{dw}$, albeit one order of magnitude below those found in the Seine estuary. Among oyster sites, the Elorn and Nivelle estuaries showed the highest HHCB median concentrations (1.17 and $1.53 \mathrm{ng} \mathrm{g}^{-1} \mathrm{dw}$, respectively). AHTN and MK showed a similar geographical distribution: besides the Seine estuary and Bay, hot spots were identified in the Elorn and Nivelle estuaries on the Atlantic coast, showing, on average, median concentrations 3 times the median values found on this coast. If the Elorn estuary sampling site is located in the vicinity of the discharge of a 170000 population-equivalent WWTP, the Nivelle estuary has a rather limited anticipated anthropogenic pressure, with a relatively low population on a small catchment area, in particular when compared to the larger Loire or Gironde estuaries of the same coast. Proximity of the sampling sites to local point sources such as urban effluent discharges (Sumner et al., 2010) or landfills (Eggen et al., 2010), in combination with the local hydrodynamics (mixing and dilution of such effluent plumes), could account for these peculiarities. In contrast with the other musks, MX interannual median concentrations show 
325 much more consistency between sites, including in the Seine estuary, with a relative 326 interquartile range between sites of $63 \%$, while HHCB, AHTN and MK showed relative Inter327 Quartile Range (IQR) of 276\% (both species together), 86\%, and 166\%, respectively. As MX 328 was banned from use in the EU in 2009-2011 (Abril, 2011), it is likely that its ubiquitous 329 presence in the marine environment results from older point source emissions, gradually 330 evened and distributed on the coast following various transport processes. For the same 331 reason, the existence of a remaining hotspot in the Nivelle estuary on the Atlantic coast 332 (highest median concentrations) is unlikely the result of a contemporary use of MX. Co333 occurring high levels of all musks at this site (including HHCB within the oyster subset, 334 Figure 3) tends to suggest that the aforementioned point source corresponds to old stocks, MX 335 high persistency (European Chemicals Agency, 2008) could cause its release in the 336 environment for a prolonged time. 

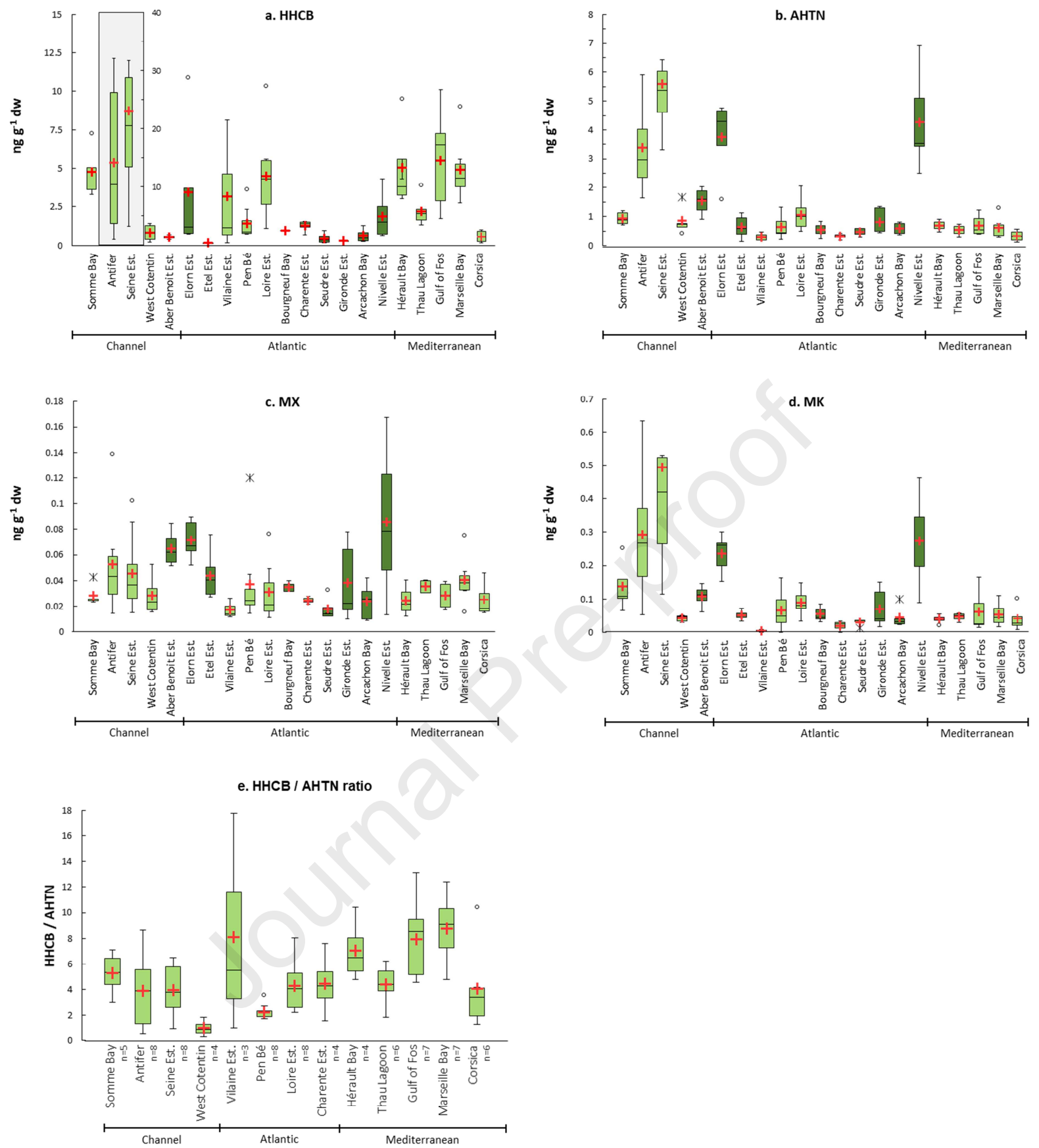

338 Figure 3. a, b, c and d: Geographical distributions of musk concentrations (ng $\mathrm{g}^{-1} \mathrm{dw}$ ) 339 determined in bivalves (mussels light green, oysters dark green) collected on the French 340 coasts between 2010 and 2019 ( $n=1$ to 8). e: Distribution of the HHCB / AHTN ratio in 341 mussels collected along French coasts between 2010 and 2019. Boxes are $1^{\text {st }}$ quartile, median 342 and $3^{\text {rd }}$ quartile, the average is plotted with a red cross and the whiskers indicate min. and 
max. values excluding outliers. Standard Outliers fall between $1.5^{*} \mathrm{IQR}$ (Inter-Quartile

344 Range) and 3.0*IQR outside of the IQR and are plotted with an open circle. Extreme Outliers

345 fall greater than 3.0*IQR outside the IQR and are plotted with an X. HHCB concentrations in

346 the Seine estuary and Bay are plotted on a distinct scale (see inset).

\subsection{HHCB / AHTN diagnostic ratio}

As previously reported in the literature, the HHCB / AHTN concentration ratio can be used to discriminate sources and environmental processes affecting polycyclic musk contamination in the environment (Buerge et al., 2003; Xie et al., 2007). Considering the species-specific accumulation previously discussed, this ratio was examined here for mussels only (Figure 3.e). The overall median ratio was 4.6 , and spanned a large range from 0.3 to 17.8 (2.2-6.4; $1^{\text {st }}-3^{\text {rd }}$ quartile). Over half of the 13 sites sampled for mussels had a relatively high interannual variability, i.e. over 50\% (IQR). In the English Channel and Atlantic coastline, lower ratios were observed for the coastal sites of West Cotentin (median 0.9) and Pen-Bé (median 1.9); with both sites located further away from urban pressures when compared with more estuarine sites (medians between 3.8 and 5.5). A similar observation can be made between the

359 Mediterranean sites, with lower ratios found in Thau lagoon (median 4.4) and Corsica 360 (median 3.4) compared to those of Hérault Bay (median 6.5), Gulf of Fos (median 8.6) and 361 Marseille Bay (median 9.1). The last three are under the influence of higher populated 362 watersheds (the Hérault river, the Rhone river and Marseille, the $2^{\text {nd }}$ most populated city in 363 France).

364 To date, this ratio has mainly been used as a global marker of WWTP influence in surface 365 waters, although various processes have to be considered in order to fully interpret its 366 variation, leading to a broad range of values. In a Swiss lake, Buerge et al. (2003) found rather 
constant ratios in WWTP effluents $(2.6 \pm 0.2)$, that increased with residence time in receiving waters (from $3.3 \pm 0.9$ to $8.1 \pm 1.4$ ), an increase attributed to the highest photodegradability of AHTN in water (HHCB having a 25-time longer phototransformation half-life). This was also hypothesised in the lower Great Lakes (USA), where higher ratios were measured in the dissolved phase further from sources (between 7-12, McDonough et al., 2016), but in apparent contradiction with observations made in the UK, where ratios of 13-18 in effluents decreased to 2.0-5.2 in the receiving coastal waters (Sumner et al., 2010). The authors attributed this decrease to the higher degradability of $\mathrm{HHCB}$, a hypothesis also supported by data from a German river (ratio of 5.0 in waters downstream a WWTP discharge, decreasing to 3.8 along the river, Lange et al., 2015). In South Korea, sewage effluents and their receiving surface waters had comparable ratios of 4.08-5.42 (Lee et al., 2010), a similar observation made in the

378 Berlin region (2.87 in effluents, 2.77 in surface waters, Heberer, 2002) and in the Las Vegas region $(1.6 \pm 0.3$ in effluents, $1.9 \pm 0.9$ in lake, Osemwengie and Gerstenberger, 2004). There is a general agreement on the finding of ratios close to 1 in air and background sites primarily under influence of atmospheric depositions, where AHTN is more stable to atmospheric oxidation processes (Lange et al., 2015; McDonough et al., 2016; Xie et al., 2007). When 383 comparing sediments and water, some authors have reported ratios closer to 1 in sediments, 384 primarily due to a stronger tendency of AHTN for sorption and/or a degradation of HHCB into its lactone derivative in sediment (Bayen et al., 2019; Heberer, 2002; Lu et al., 2015).

386 Other studies measured an opposite trend, with no evident explanatory factor (Zhang et al., 387 2020). In light of this literature, the geographical differences of the HHCB / AHTN ratio 388 determined in our study (i.e. higher ratios in areas under stronger anthropogenic pressure) 389 support a higher removal of HHCB with increasing distance from sources, and/or higher 390 inputs of AHTN through the relative higher contribution of atmospheric influence (both dry 391 and wet deposition). This is also in agreement with our understanding of the pressures 
affecting these studied sites - a knowledge acquired through the long-term monitoring of

393 various hydrophobic contaminants (see Munschy et al., 2019, 2015, 2013). Interestingly, 394 when considered all sampling years, significantly higher values were found in the

395 Mediterranean sites compared to the English Channel and Atlantic coast sites, with average 396 values in the Mediterranean 1.8 and 1.6 times higher than in the English Channel and Atlantic 397 coast, respectively. In particular, the average ratios in Marseille Bay and the Gulf of Fos were 3982.0 to 2.3 times higher than those in the Seine and Loire estuaries. Assuming likely 399 comparable sources in the Atlantic and Mediterranean shores (musk uses and effluent composition), lower HHCB / AHTN ratios in the macrotidal Seine and Loire estuaries could be attributed to a more pronounced degradation of HHCB due to the long residence time of 402 waters in such hydrosystems, and the high turbidity where particle-born bacteria promote 403 biodegradation of the less recalcitrant compounds (Aminot et al., 2018, 2016). Stronger 404 removal of AHTN through photolysis in the sunnier climate of the Mediterranean shore sites could also account for the general observed trend.

\subsection{Temporal trends}

As datasets with a minimum of 4 time points have been recommended for trend evaluation, and 7 for change point analysis (Land et al., 2018), our 8-year time series allows a robust

409 examination of the temporal trends of musks in the environment. Only the 7 sites for which a 410 maximum of 1 datapoint was missing (<LOQ) were selected for a monotonous trend analysis 411 using the Mann-Kendall non-parametric test (Figure 4).

412 MX concentrations were found to be significantly decreasing in 5 sites (confidence factor 413 between 91 and 99\%), whilst no trend could be fitted in the Gulf of Fos. The concentrations 414 measured at most sites over the first 2 years of monitoring were generally higher than the 415 following 6 , and it is worth noting that all decreasing trends become stable if these first 2 
years are not considered. With caution over these 2 years driving the trend, the results

417 observed for MX probably reflect the regulations on this chemical. MX is banned by EU since

418 2011, and its use was not approved by fragrance industrials since the late 2000's (Abril,

419 2011), but early substitutions started in the mid 1990's (Käfferlein and Angerer, 2001). MX

420 levels were found to decrease in human plasma collected in Germany between 1992 and 1998

421 (Käfferlein and Angerer, 2001) and in mother's milk in Sweden in the late 1990's (Lignell et

422 al., 2008), indicating that the use of MX declined prior to its ban. In freshwater biota (bream),

423 MX was found to decrease in Germany between 1993 and 1999 (Rüdel et al., 2006). Within

424 lake sediment cores, MX was also found to decrease in the last decades, but their large core

425 time resolution prevents the determination of a clear change point (Peck et al., 2006). The

426 absence of a contemporary use of MX is in agreement with its lower geographical variability

427 observed in our study. This indicates that, similarly to other regulated persistent compounds,

428 current MX concentrations most likely result from its high stability towards both abiotic (Gao

429 et al., 2019) and biotic degradation (Tas et al., 1997). Conversely, HHCB concentration trends

430 were found to be stable (or have no trend) in the 7 sites considered, as well as MK's and

431 AHTN's in 6 and 5 sites, respectively, for which the remaining sites were found to be

432 decreasing with a 91-97\% confidence factor. The absence of significant time trends and the

433 existence of "hot spots" related to anthropogenic pressures indicate current use and

434 continuous inputs of these 3 contaminants. As a constant release of persistent compounds

435 should result in the increase of their environmental concentrations, the absence of an

436 increasing time-trend could suggest a better degradability of musks compared with other

437 POPs. Recent trend analysis of musks are relatively scarce in the literature and are somewhat

438 conflicting for polycyclic musks, potentially as a result of different practises and regulations

439 worldwide (see Gatermann et al., 1999, and Nakata et al., 2012). In the USA, Mytilus edulis

440 specimens collected between 1991 and 2005 in an urban tidal estuary showed significantly 
441 decreasing concentrations for both HHCB and AHTN (Subedi et al., 2014), whilst lake

442 sediments concentrations revealed an opposite increasing trend over the investigated period 443 (1990-2003), showing correlation with production data (Peck et al., 2006). Similarly, in a 444 survey from the 1970 's to 2005 , HHCB concentrations in marine mammals have increased 445 significantly since the 1990s in Japanese waters (Nakata et al., 2007). A study on various 446 marine and freshwater organisms in Germany over the earlier 1986-2000 period only found 447 trace levels of musks in mussels, with no exploitable time trend, while HHCB and AHTN 448 levels showed decreasing levels in bream (Abramis brama) in the late 1990s, with AHTN 449 concentrations decreasing faster than HHCB's (Rüdel et al., 2006). In Sweden, AHTN was 450 found to decline significantly in mother's milk between 1996 and 2003 (Lignell et al., 2008), 451 whilst an increase of HHCB concentrations in sewage sludge was found between 2005 and 4522015 and was attributed to increase in its use (Veenaas et al., 2018). On the other hand, time trends of MK are lacking, except a decrease reported in bream in Germany in the mid-1990's 454 (Rüdel et al., 2006). This lack of information is probably caused by its trace-level 455 concentrations in the environment and by the assumption that nitro-musks have been entirely 456 substituted by polycyclic musks (Lange et al., 2015), dissuading its monitoring. However, 457 according to ECHA, MK is still produced/imported in EU between $100-1000$ tonnes per 458 annum (ECHA, 2020), consistent with our data indicating no decreasing trend over the 8 459 years investigated. 

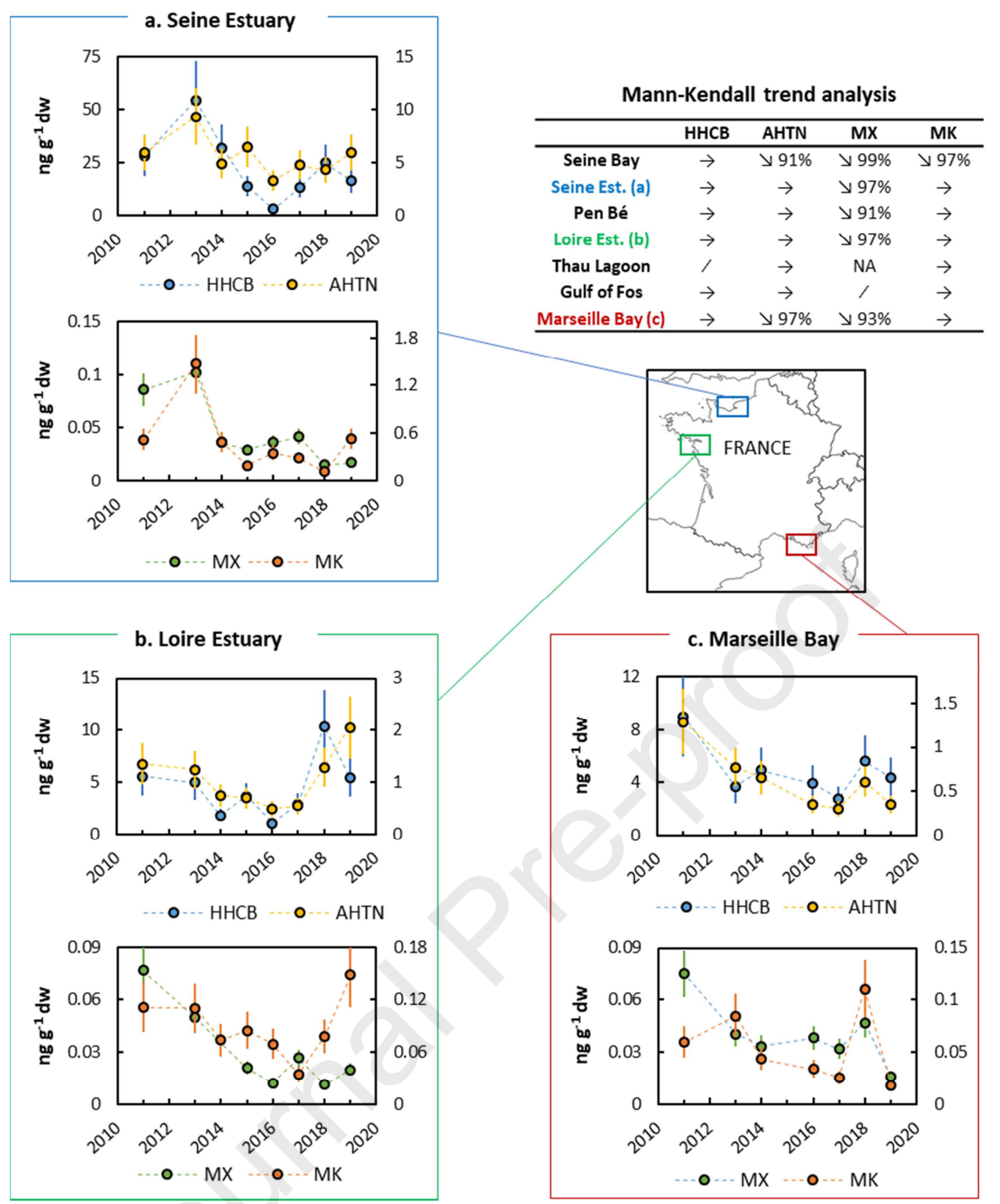

462 Figure 4. Temporal trends of the 4 musks in the sites with a minimum of 7 annual datapoints

463 (6 in Mediterranean sites). Concentrations are given in a, b and c for 3 selected sites in $\mathrm{ng} \mathrm{g}^{-1}$ $464 \mathrm{dw}$. The left Y-axis are given for HHCB and MX, the right Y-axis for AHTN and MK. The 465 trends and confidence factors of the Mann-Kendall statistic at all sites are provided in the table. 
Our study has shown evidence of widespread contamination of coastal bivalves by synthetic musks, with a predominance of polycyclic over nitro-musks. Contrary to AHTN, MK and

471 MX, significant differences of HHCB concentrations between mussel- and oyster-monitored 472 sites suggest its species-specific accumulation potentially related to metabolization, and 473 warrants further research. With wastewater as the major source of musks in the environment, 474 the geographical distributions observed reflected the urban pressure, with the Seine estuary 475 showing the highest concentrations of HHCB, AHTN and MK. Conversely, more consistent concentrations of MX among the sites indicated background concentrations in agreement with

477 its restricted use and its persistence. In addition to be indicative of species-specific 478 bioaccumulation of HHCB, HHCB / AHTN ratio was proven to be a relevant marker of 479 sources and processes affecting their environmental occurrence levels. Our 8-year monitoring 480 afforded the evaluation of a robust time-trend and revealed a significant decrease for MX 481 only, when concentrations of HHCB, AHTN and MK remained stable. Without further 482 regulations or change in consumers' practices, synthetic musks are likely to remain 483 contaminants of concern in the near future They should receive a wider attention from the 484 marine research community and be included in marine biomonitoring programs.

\section{Acknowledgements}

487 The authors would like to thank the OFB (Office Français de la Biodiversité) for its financial 488 support. IFREMER staff from coastal laboratories and Anne Grouhel, in charge of the 489 coordination of the French Mussel Watch network, are gratefully acknowledged for 490 performing and coordinating the sampling campaigns, respectively.

\section{References}


Abril, J., 2011. Musk Xylene Ban. Chemical \& Engineering News 89, 3.

Aminot, Y., Fuster, L., Pardon, P., Le Menach, K., Budzinski, H., 2018. Suspended solids moderate the degradation and sorption of waste water-derived pharmaceuticals in estuarine waters. Science of The Total Environment 612, 39-48. https://doi.org/10.1016/j.scitotenv.2017.08.162

Aminot, Y., Le Menach, K., Pardon, P., Etcheber, H., Budzinski, H., 2016. Inputs and seasonal removal of pharmaceuticals in the estuarine Garonne River. Marine Chemistry, 13th International Estuarine Biogeochemistry Symposium (IEBS) Estuaries Under Anthropogenic Pressure 185, 3-11. https://doi.org/10.1016/j.marchem.2016.05.010

Aminot, Y., Sayfritz, S.J., Thomas, K.V., Godinho, L., Botteon, E., Ferrari, F., Boti, V., Albanis, T., Köck-Schulmeyer, M., Diaz-Cruz, M.S., Farré, M., Barceló, D., Marques, A., Readman, J.W., 2019. Environmental risks associated with contaminants of legacy and emerging concern at European aquaculture areas. Environmental Pollution 252, 1301-1310. https://doi.org/10.1016/j.envpol.2019.05.133

Bayen, S., Segovia Estrada, E., Zhang, H., Lee, W.K., Juhel, G., Smedes, F., Kelly, B.C., 2019. Partitioning and Bioaccumulation of Legacy and Emerging Hydrophobic Organic Chemicals in Mangrove Ecosystems. Environ. Sci. Technol. 53, 2549-2558. https://doi.org/10.1021/acs.est.8b06122

Bester, K., 2009. Analysis of musk fragrances in environmental samples. Journal of Chromatography A, Tools for the REACH Programme - analytical methods for the evaluation of industrial contaminants $1216,470-480$. https://doi.org/10.1016/j.chroma.2008.08.093

Beyer, J., Green, N.W., Brooks, S., Allan, I.J., Ruus, A., Gomes, T., Bråte, I.L.N., Schøyen, M., 2017. Blue mussels (Mytilus edulis spp.) as sentinel organisms in coastal pollution monitoring: A review. Marine Environmental Research 130, 338-365. https://doi.org/10.1016/j.marenvres.2017.07.024

Booij, K., Zegers, B.N., Boon, J.P., 2002. Levels of some polybrominated diphenyl ether (PBDE) flame retardants along the Dutch coast as derived from their accumulation in SPMDs and blue mussels (Mytilus edulis). Chemosphere 46, 683-688. https://doi.org/10.1016/S0045-6535(01)00232-6

Buerge, I.J., Buser, H.-R., Müller, M.D., Poiger, T., 2003. Behavior of the Polycyclic Musks HHCB and AHTN in Lakes, Two Potential Anthropogenic Markers for Domestic Wastewater in Surface Waters. Environ. Sci. Technol. 37, 5636-5644. https://doi.org/10.1021/es0300721

Casatta, N., Mascolo, G., Roscioli, C., Viganò, L., 2015. Tracing endocrine disrupting chemicals in a coastal lagoon (Sacca di Goro, Italy): sediment contamination and bioaccumulation in Manila clams. Sci. Total Environ. 511, 214-222. https://doi.org/10.1016/j.scitotenv.2014.12.051

Castro, M., Fernandes, J.O., Pena, A., Cunha, S.C., 2018. Occurrence, profile and spatial distribution of UV-filters and musk fragrances in mussels from Portuguese coastline. Marine Environmental Research 138, 110-118. https://doi.org/10.1016/j.marenvres.2018.04.005

Cousins, I.T., Ng, C.A., Wang, Z., Scheringer, M., 2019. Why is high persistence alone a major cause of concern? Environ. Sci.: Processes Impacts 21, 781-792. https://doi.org/10.1039/C8EM00515J

Cunha, S.C., Fernandes, J.O., Vallecillos, L., Cano-Sancho, G., Domingo, J.L., Pocurull, E., Borrull, F., Maulvault, A.L., Ferrari, F., Fernandez-Tejedor, M., Van den Heuvel, F., Kotterman, M., 2015. Co-occurrence of musk fragrances and UV-filters in seafood and macroalgae collected in European hotspots. Environmental Research, Non- 
regulated environmental contaminants in seafood: contributions of the

ECsafeSEAFOOD EU project 143, 65-71.

https://doi.org/10.1016/j.envres.2015.05.003

Dodder, N.G., Maruya, K.A., Lee Ferguson, P., Grace, R., Klosterhaus, S., La Guardia, M.J., Lauenstein, G.G., Ramirez, J., 2014. Occurrence of contaminants of emerging concern in mussels (Mytilus spp.) along the California coast and the influence of land use, storm water discharge, and treated wastewater effluent. Marine Pollution Bulletin, U.S. Coastal Monitoring: NOAA's Mussel Watch investigates Contaminants of Emerging Concern 81, 340-346. https://doi.org/10.1016/j.marpolbul.2013.06.041

Eggen, T., Moeder, M., Arukwe, A., 2010. Municipal landfill leachates: A significant source for new and emerging pollutants. Science of The Total Environment 408, 5147-5157. https://doi.org/10.1016/j.scitotenv.2010.07.049

EU, 2008a. AHTN Risk Assessment Report.

EU, 2008b. HHCB Risk Assessment Report.

European Chemicals Agency, 2008. Support Document for Identification of 5-tert-Butyl2,4,6-trinitro-m-xylene as a Substance of Very High Concern.

Farrington, J.W., Tripp, B.W., Tanabe, S., Subramanian, A., Sericano, J.L., Wade, T.L., Knap, A.H., 2016. Edward D. Goldberg's proposal of "the Mussel Watch": Reflections after 40years. Marine Pollution Bulletin 110, 501-510. https://doi.org/10.1016/j.marpolbul.2016.05.074

Fernandes, D., Dimastrogiovanni, G., Blázquez, M., Porte, C., 2013. Metabolism of the polycyclic musk galaxolide and its interference with endogenous and xenobiotic metabolizing enzymes in the European sea bass (Dicentrarchus labrax). Environmental Pollution 174, 214-221. https://doi.org/10.1016/j.envpol.2012.11.033

Ferrario, C., Finizio, A., Villa, S., 2017. Legacy and emerging contaminants in meltwater of three Alpine glaciers. Science of The Total Environment 574, 350-357. https://doi.org/10.1016/j.scitotenv.2016.09.067

Gao, Y., Li, G., Qin, Y., Ji, Y., Mai, B., An, T., 2019. New theoretical insight into indirect photochemical transformation of fragrance nitro-musks: Mechanisms, eco-toxicity and health effects. Environment International 129, 68-75. https://doi.org/10.1016/j.envint.2019.05.020

Gatermann, R., Biselli, S., Hühnerfuss, H., Rimkus, G.G., Hecker, M., Karbe, L., 2002. Synthetic musks in the environment. Part 1: Species-dependent bioaccumulation of polycyclic and nitro musk fragrances in freshwater fish and mussels. Arch. Environ. Contam. Toxicol. 42, 437-446. https://doi.org/10.1007/s00244-001-0041-2

Gatermann, R., Hellou, J., Hühnerfuss, H., Rimkus, G., Zitko, V., 1999. Polycyclic and nitro musks in the environment: A comparison between Canadian and European aquatic biota. Chemosphere 38, 3431-3441. https://doi.org/10.1016/S0045-6535(98)00564-5

Heberer, T., 2002. Occurrence, Fate, and Assessment of Polycyclic Musk Residues in the Aquatic Environment of Urban Areas - A Review. Acta hydrochimica et hydrobiologica 30, 227-243. https://doi.org/10.1002/aheh.200390005

Homem, V., Silva, J.A., Ratola, N., Santos, L., Alves, A., 2015. Long lasting perfume - A review of synthetic musks in WWTPs. Journal of Environmental Management 149, 168-192. https://doi.org/10.1016/j.jenvman.2014.10.008

Howard, P.H., Muir, D.C.G., 2010. Identifying New Persistent and Bioaccumulative Organics Among Chemicals in Commerce. Environ. Sci. Technol. 44, 2277-2285. https://doi.org/10.1021/es903383a

Isobe, T., Ogawa, S.P., Ramu, K., Sudaryanto, A., Tanabe, S., 2012. Geographical distribution of non-PBDE-brominated flame retardants in mussels from Asian coastal 
waters. Environ Sci Pollut Res 19, 3107-3117. https://doi.org/10.1007/s11356-0120945-6

Käfferlein, H.U., Angerer, J., 2001. Trends in the musk xylene concentrations in plasma samples from the general population from 1992/1993 to 1998 and the relevance of dermal uptake. Int Arch Occup Environ Health 74, 470-476. https://doi.org/10.1007/s004200100257

Lange, C., Kuch, B., Metzger, J.W., 2015. Occurrence and fate of synthetic musk fragrances in a small German river. Journal of Hazardous Materials, Advances in Analysis, Treatment Technologies, and Environmental Fate of Emerging Contaminants 282, 3440. https://doi.org/10.1016/j.jhazmat.2014.06.027

Lee, I.-S., Kim, U.-J., Oh, J.-E., Choi, M., Hwang, D.-W., 2014. Comprehensive monitoring of synthetic musk compounds from freshwater to coastal environments in Korea: With consideration of ecological concerns and bioaccumulation. Science of The Total Environment 470-471, 1502-1508. https://doi.org/10.1016/j.scitotenv.2013.07.070

Lee, I.-S., Lee, S.-H., Oh, J.-E., 2010. Occurrence and fate of synthetic musk compounds in water environment. Water Research 44, 214-222. https://doi.org/10.1016/j.watres.2009.08.049

Lignell, S., Darnerud, P.O., Aune, M., Cnattingius, S., Hajslova, J., Setkova, L., Glynn, A., 2008. Temporal Trends of Synthetic Musk Compounds in Mother's Milk and Associations with Personal Use of Perfumed Products. Environ. Sci. Technol. 42, 6743-6748. https://doi.org/10.1021/es800626n

Liu, J., Zhang, W., Zhou, Qixing, Zhou, Qingqin, Zhang, Y., Zhu, L., 2020. Polycyclic musks in the environment: A review of their concentrations and distribution, ecological effects and behavior, current concerns and future prospects. Critical Reviews in Environmental Science and Technology 0, 1-55. https://doi.org/10.1080/10643389.2020.1724748

Lu, B., Feng, Y., Gao, P., Zhang, Z., Lin, N., 2015. Distribution and fate of synthetic musks in the Songhua River, Northeastern China: influence of environmental variables. Environ Sci Pollut Res 22, 9090-9099. https://doi.org/10.1007/s11356-014-3973-6

McDonough, C.A., Helm, P.A., Muir, D., Puggioni, G., Lohmann, R., 2016. Polycyclic Musks in the Air and Water of the Lower Great Lakes: Spatial Distribution and Volatilization from Surface Waters. Environ. Sci. Technol. 50, 11575-11583. https://doi.org/10.1021/acs.est.6b03657

Melymuk, L., Robson, M., Csiszar, S.A., Helm, P.A., Kaltenecker, G., Backus, S., Bradley, L., Gilbert, B., Blanchard, P., Jantunen, L., Diamond, M.L., 2014. From the City to the Lake: Loadings of PCBs, PBDEs, PAHs and PCMs from Toronto to Lake Ontario. Environ. Sci. Technol. 48, 3732-3741. https://doi.org/10.1021/es403209z

Munschy, C., Bely, N., Pollono, C., Aminot, Y., 2019. Perfluoroalkyl substances (PFASs) in the marine environment: Spatial distribution and temporal profile shifts in shellfish from French coasts. Chemosphere 228, 640-648. https://doi.org/10.1016/j.chemosphere.2019.04.205

Munschy, C., Marchand, P., Venisseau, A., Veyrand, B., Zendong, Z., 2013. Levels and trends of the emerging contaminants HBCDs (hexabromocyclododecanes) and PFCs (perfluorinated compounds) in marine shellfish along French coasts. Chemosphere 91, 233-240. https://doi.org/10.1016/j.chemosphere.2012.12.063

Munschy, C., Olivier, N., Veyrand, B., Marchand, P., 2015. Occurrence of legacy and emerging halogenated organic contaminants in marine shellfish along French coasts. Chemosphere 118, 329-335. https://doi.org/10.1016/j.chemosphere.2014.09.106

Nakata, H., Hinosaka, M., Yanagimoto, H., 2015. Macrocyclic-, polycyclic-, and nitro musks in cosmetics, household commodities and indoor dusts collected from Japan: 
Implications for their human exposure. Ecotoxicology and Environmental Safety 111, 248-255. https://doi.org/10.1016/j.ecoenv.2014.09.032

Nakata, H., Sasaki, H., Takemura, A., Yoshioka, M., Tanabe, S., Kannan, K., 2007. Bioaccumulation, Temporal Trend, and Geographical Distribution of Synthetic Musks in the Marine Environment. Environ. Sci. Technol. 41, 2216-2222. https://doi.org/10.1021/es0623818

Nakata, H., Shinohara, R.-I., Nakazawa, Y., Isobe, T., Sudaryanto, A., Subramanian, A., Tanabe, S., Zakaria, M.P., Zheng, G.J., Lam, P.K.S., Kim, E.Y., Min, B.-Y., We, S.U., Viet, P.H., Tana, T.S., Prudente, M., Frank, D., Lauenstein, G., Kannan, K., 2012. Asia-Pacific mussel watch for emerging pollutants: Distribution of synthetic musks and benzotriazole UV stabilizers in Asian and US coastal waters. Marine Pollution Bulletin 64, 2211-2218. https://doi.org/10.1016/j.marpolbul.2012.07.049

Osemwengie, L.I., Gerstenberger, S.L., 2004. Levels of synthetic musk compounds in municipal wastewater for potential estimation of biota exposure in receiving waters. J. Environ. Monit. 6, 533-539. https://doi.org/10.1039/B400514G

OSPAR, 2019. The OSPAR list of chemicals for priority action : Suggestions for future actions.

OSPAR, 2018. CEMP Guidelines for Monitoring Contaminants in Biota (Agreement 199902). Revision 2018.

OSPAR, 2008. Towards the cessation target: Emissions, discharges and losses of OSPAR chemicals identified for priority action.

Peck, A.M., Linebaugh, E.K., Hornbuckle, K.C., 2006. Synthetic Musk Fragrances in Lake Erie and Lake Ontario Sediment Cores. Environ. Sci. Technol. 40, 5629-5635. https://doi.org/10.1021/es060134y

Picot Groz, M., Martinez Bueno, M.J., Rosain, D., Fenet, H., Casellas, C., Pereira, C., Maria, V., Bebianno, M.J., Gomez, E., 2014. Detection of emerging contaminants (UV filters, UV stabilizers and musks) in marine mussels from Portuguese coast by QuEChERS extraction and GC-MS/MS. Science of The Total Environment 493, 162-169. https://doi.org/10.1016/j.scitotenv.2014.05.062

Pintado-Herrera, M.G., Allan, I.J., González-Mazo, E., Lara-Martín, P.A., 2020. Passive Samplers vs Sentinel Organisms: One-Year Monitoring of Priority and Emerging Contaminants in Coastal Waters. Environ. Sci. Technol. 54, 6693-6702. https://doi.org/10.1021/acs.est.0c00522

Reiner, J.L., Kannan, K., 2006. A survey of polycyclic musks in selected household commodities from the United States. Chemosphere 62, 867-873. https://doi.org/10.1016/j.chemosphere.2005.10.006

Rüdel, H., Böhmer, W., Schröter-Kermani, C., 2006. Retrospective monitoring of synthetic musk compounds in aquatic biota from German rivers and coastal areas. Journal of Environmental Monitoring 8, 812-823. https://doi.org/10.1039/B602389B

Sanchez-Prado, L., Llompart, M., Lamas, J.P., Garcia-Jares, C., Lores, M., 2011. Multicomponent analytical methodology to control phthalates, synthetic musks, fragrance allergens and preservatives in perfumes. Talanta $85,370-379$. https://doi.org/10.1016/j.talanta.2011.03.079

Saraiva, M., Cavalheiro, J., Lanceleur, L., Monperrus, M., 2016. Synthetic musk in seafood products from south Europe using a quick, easy, cheap, effective, rugged and safe extraction method. Food Chemistry 200, 330-335. https://doi.org/10.1016/j.foodchem.2016.01.017

Subedi, B., Yun, S., Jayaraman, S., Bergen, B.J., Kannan, K., 2014. Retrospective monitoring of persistent organic pollutants, including PCBs, PBDEs, and polycyclic musks in blue mussels (Mytilus edulis) and sediments from New Bedford Harbor, Massachusetts, 
USA: 1991-2005. Environ Monit Assess 186, 5273-5284. https://doi.org/10.1007/s10661-014-3776-8

Sumner, N.R., Guitart, C., Fuentes, G., Readman, J.W., 2010. Inputs and distributions of synthetic musk fragrances in an estuarine and coastal environment; a case study. Environmental Pollution 158, 215-222. https://doi.org/10.1016/j.envpol.2009.07.018 Tappin, A.D., Millward, G.E., 2015. The English Channel: Contamination status of its transitional and coastal waters. Marine Pollution Bulletin, The English Channel and it's catchments: Status and Responses to Contaminants 95, 529-550. https://doi.org/10.1016/j.marpolbul.2014.12.012

Tas, J.W., Balk, F., Ford, R.A., van de Plassche, E.J., 1997. Environmental risk assessment of musk ketone and musk xylene in the Netherlands in accordance with the EU-TGD. Chemosphere 35, 2973-3002. https://doi.org/10.1016/S0045-6535(97)00261-0

Trabalón, L., Cano-Sancho, G., Pocurull, E., Nadal, M., Domingo, J.L., Borrull, F., 2015. Exposure of the population of Catalonia (Spain) to musk fragrances through seafood consumption: Risk assessment. Environmental Research, Non-regulated environmental contaminants in seafood: contributions of the ECsafeSEAFOOD EU project 143, 116-122. https://doi.org/10.1016/j.envres.2015.04.007

Tumová, J., Šauer, P., Golovko, O., Koba Ucun, O., Grabic, R., Máchová, J., Kocour Kroupová, H., 2019. Effect of polycyclic musk compounds on aquatic organisms: A critical literature review supplemented by own data. Science of The Total Environment 651, 2235-2246. https://doi.org/10.1016/j.scitotenv.2018.10.028

Vallecillos, L., Pocurull, E., Borrull, F., 2015. Influence of pre-treatment process on matrix effect for the determination of musk fragrances in fish and mussel. Talanta 134, 690698. https://doi.org/10.1016/j.talanta.2014.12.010

Veenaas, C., Bignert, A., Liljelind, P., Haglund, P., 2018. Nontarget Screening and TimeTrend Analysis of Sewage Sludge Contaminants via Two-Dimensional Gas Chromatography-High Resolution Mass Spectrometry. Environ. Sci. Technol. 52, 7813-7822. https://doi.org/10.1021/acs.est.8b01126

Weinberg, I., Dreyer, A., Ebinghaus, R., 2011. Waste water treatment plants as sources of polyfluorinated compounds, polybrominated diphenyl ethers and musk fragrances to ambient air. Environmental Pollution 159, 125-132. https://doi.org/10.1016/j.envpol.2010.09.023

Wong, F., Robson, M., Melymuk, L., Shunthirasingham, C., Alexandrou, N., Shoeib, M., Luk, E., Helm, P., Diamond, M.L., Hung, H., 2019. Urban sources of synthetic musk compounds to the environment. Environmental Science: Processes and Impacts 21, 74-88. https://doi.org/10.1039/c8em00341f

Xie, Z., Ebinghaus, R., Temme, C., Heemken, O., Ruck, W., 2007. Air-Sea Exchange Fluxes of Synthetic Polycyclic Musks in the North Sea and the Arctic. Environ. Sci. Technol. 41, 5654-5659. https://doi.org/10.1021/es0704434

Zhang, H., Bu, Q., Wu, D., Yu, G., 2020. Polycyclic musks in surface water and sediments from an urban catchment in the megacity Beijing, China. Environmental Pollution 263, 114548. https://doi.org/10.1016/j.envpol.2020.114548 
Levels and trends of synthetic musks in marine bivalves from French coastal areas

Yann Aminot ${ }^{1}$, Catherine Munschy ${ }^{1}$, Karine Héas-Moisan ${ }^{1}$, Charles Pollono ${ }^{1}$, Céline Tixier $^{1}$

1 IFREMER (Institut Français de Recherche pour l'Exploitation de la Mer), Laboratory of Biogeochemistry of Organic Contaminants, Rue de l'Ile d'Yeu, BP 21105, Nantes Cedex 3, 44311, France 
For each batch of 8-10 analyses, one procedural blank and one in-house spiked reference material were extracted. Because synthetic musks are volatile compounds of daily use, their quantification in procedural blanks is not uncommon (Bester, 2009). Despite sample handling in a clean laboratory environment, HHCB and AHTN were detected in the procedural blanks of all series (Fig S1), whilst MX and MK were undetected. HHCB and AHTN were found at average concentrations between $0.053-0.177 \mathrm{ng} \mathrm{g}^{-1} \mathrm{dw}$ and $0.011-0.088 \mathrm{ng} \mathrm{g}^{-1} \mathrm{dw}$ in samples from 2015 onwards. Improvement from the first year's values (average blank levels from 2010 to 2014 were $0.315-0.525$ and $0.119-0.149 \mathrm{ng} \mathrm{g}^{-1} \mathrm{dw}$ for HHCB, and AHTN, respectively) was achieved by the implementation of stricter protocols including: thorough rinsing of glassware and conditioning of silica and alumina sorbents, use of fresh solvent bottles, and, limited use of personal care products by participating staff. Concentrations in samples were systematically corrected for blank contamination: the mass of analyte (ng) found in the blanks was subtracted from the mass (ng) found in the samples, provided that the analyte mass in the sample was above 3 times the blanks'. By definition, the blank then represents under $33 \%$ of the uncorrected sample analyte mass. For HHCB, the blank analyte mass falls below $5 \%$ of the sample analyte mass for over half of the measurements; for AHTN, the blank analyte mass falls below $4 \%$ of the sample analyte mass for over half of the measurements.
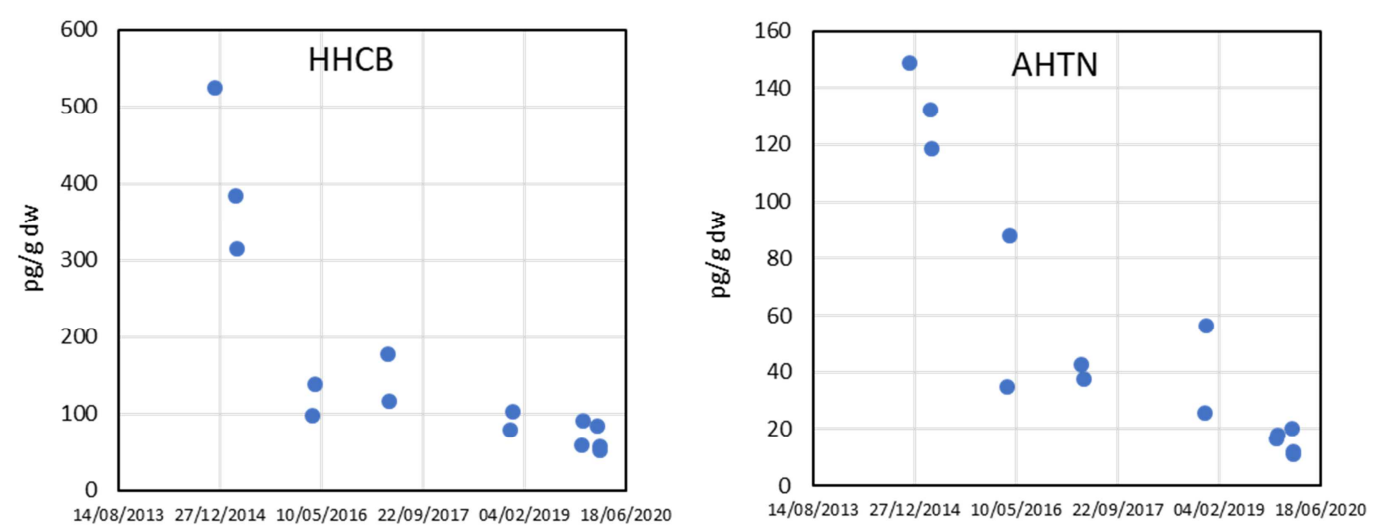
Figure S1. Blank value control chart.

In the absence of commercially available reference materials for musk analysis, the in-house spiked reference material was prepared from pooled mussels collected from a low-impacted area and enriched at final environmental levels of 2.00, 1.50, 0.050 and $0.10 \mathrm{ng} \mathrm{g}^{-1} \mathrm{dw}$ for HHCB, AHTN, MX and MK, respectively. Average accuracies $(n=11)$ were $99 \pm 6,98 \pm 5$, $93 \pm 8$ and $95 \pm 4 \%$ for HHCB, AHTN, MX and MK, respectively, and never higher than 114 $\%$ or lower than $84 \%$. Attenuation in HHCB concentrations in this spiked in-house reference material was found to occur, with $10-20 \%$ lower concentrations after 1 year of storage (dark, air-tight, glass jar, room temperature). For this reason, field samples were analysed within 12 months, except for the 92010 samples, analysed in 2013.

Spiked experiment on mussels and oysters were also conducted to investigate the possibility of a species-specific matrix effect. Triplicates of mussel and oyster samples from a lowimpacted background site of the Atlantic coast were enriched with the 4 target analytes at concentrations comparable to those found in mussels from contaminated sites (target values of 3.5, 3.5, 0.35 and $0.35 \mathrm{ng} / \mathrm{g} \mathrm{dw}$ of HHCB, AHTN, MX and MK, when raw unspiked materials were $<0.2,<0.2,<0.02$ and $<0.02 \mathrm{ng} / \mathrm{g} \mathrm{dw}$, respectively). The spiked samples were then extracted, analysed and quantified as blind samples. The results (Fig S2) indicated recoveries of the spiked compounds within an 86-102\% agreement of the target value, with no speciesspecific difference.

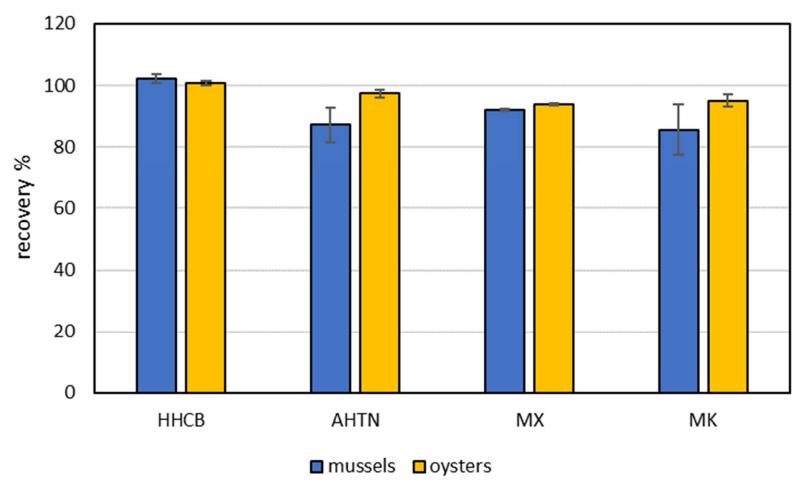


Fig S2. Recoveries of spiked compounds in mussel $(n=3)$ and oyster samples $(n=3)$.

The use of 2 different instrumental techniques for HHCB, AHTN and MK was validated over 69 field and in-house QC samples. Concentrations in average agreement of $102 \pm 18,113 \pm$ 22 and $104 \pm 31 \%$, respectively, validated their comparability and inclusion within a unique time-series. The recoveries of the internal standard MX-d15 in all samples (including in-house QC) were on average $109 \pm 13 \%(\min 81, \max 139 \%, \mathrm{n}=133)$, and reached $95 \pm 4 \%$ in the optimal conditions using MX-d9 as an injection standard and APCI-MS/MS ( $n=47)$. Limits of quantification (LOQs) were calculated for each sample, and were between 0.11-0.54, 0.023-0.29, 0.007-0.029 and 0.006-0.055 $\mathrm{ng} \mathrm{g}^{-1} \mathrm{dw}$ for HHCB, AHTN, MX and MK, respectively from 2015 onwards. Related to the above-mentioned improvement of protocols from 2015, LOQs were between $0.42-1.77,0.16-0.503,0.014-0.041$ and $0.019-0.077 \mathrm{ng} \mathrm{g}^{-1}$ $\mathrm{dw}$ in 2010-2014 samples.

Additional QA/QC criteria were: i) signal to noise ratio > 3 for the lower-intensity ion signal of each target analyte; ii) qualifier to quantifier ratio within $20 \%$ of the standard value; iii) variability of relative response factors below $10 \%$.

Despite the fact that synthetic musks are lipophilic compounds, the lipid percentage determined gravimetrically as the extractable organic matter using a mixture of $n$ hexane/acetone $(80 / 20$ volume/volume $[\mathrm{v} / \mathrm{v}])$ in the bivalve samples was constant $(9.0 \pm 2.2 \%$ dw), and showed no significant differences between species, therefore excluding any issue regarding the interpretation of results. The concentrations were therefore considered on a dw basis. 
Table S1. Dry weight percentage (\%). M: mussels, O: oysters.

\begin{tabular}{|l|l|l|l|l|l|l|l|l|}
\hline Site & 2019 & 2018 & 2017 & 2016 & 2015 & 2014 & 2013 & 2010 \\
\hline Somme Bay (M) & 28.9 & 27.0 & 28.1 & & 29.3 & 30.8 & 28.0 & \\
\hline Antifer (M) & 26.3 & 28.5 & 27.1 & 29.9 & 28.0 & 26.8 & 28.0 & 28.0 \\
\hline Seine Est. (M) & 28.6 & 29.3 & 28.1 & 31.6 & 26.6 & 29.6 & 25.8 & 22.0 \\
\hline West Cotentin (M) & 22.3 & 25.5 & 22.3 & 23.7 & 22.8 & 23.9 & 25.7 & \\
\hline Aber Benoit Est. (O) & 25.6 & 19.7 & 26.9 & 21.3 & 19.4 & 24.8 & 24.5 & \\
\hline Elorn Est. (O) & 24.8 & 23.9 & 24.8 & 22.2 & 21.6 & 22.2 & 20.1 & \\
\hline Etel Est. (O) & 22.7 & 22.5 & 22.6 & 22.3 & 22.2 & 20.0 & 20.3 & \\
\hline Vilaine Est. (M) & 27.9 & 29.0 & 28.3 & 27.7 & & & & \\
\hline Pen Bé (M) & 21.8 & 22.7 & 21.4 & 24.2 & 19.1 & 23.2 & 25.8 & 20.7 \\
\hline Loire Est. (M) & 22.8 & 23.3 & 23.8 & 20.3 & 23.2 & 23.2 & 18.3 & 20.5 \\
\hline Bourgneuf Bay (O) & 24.3 & 22.9 & 19.7 & 16.2 & 20.4 & 19.9 & 18.4 & \\
\hline Charente Est. (M) & 26.9 & 27.5 & 29.3 & 27.9 & 24.8 & 25.5 & 28.8 & \\
\hline Seudre Est. (O) & 23.0 & 16.1 & 19.0 & 23.2 & 17.7 & 21.3 & 19.9 & \\
\hline Gironde Est. (O) & 20.4 & 18.0 & & 18.1 & 18.5 & 18.6 & 16.7 & 16.3 \\
\hline Arcachon Bay (O) & 21.4 & 18.9 & 17.0 & 16.2 & 15.8 & 14.0 & 12.5 & 21.5 \\
\hline Nivelle Est. (O) & 16.7 & 17.7 & 17.3 & 17.7 & 16.1 & 17.9 & 12.0 & 21.5 \\
\hline Hérault Bay (M) & 19.6 & 19.3 & 17.2 & 16.0 & & 17.9 & 17.6 & \\
\hline Thau Lagoon (M) & 20.3 & 17.7 & 20.4 & 17.8 & & 20.8 & 21.5 & \\
\hline Gulf of Fos (M) & 18.5 & 18.8 & 17.0 & 19.4 & & 19.5 & 19.3 & 20.2 \\
\hline Marseille Bay (M) & 20.2 & 18.7 & 21.5 & 19.7 & & 17.1 & 17.9 & 21.0 \\
\hline Corsica (M) & & 21.2 & 19.6 & 20.6 & & 22.6 & 20.0 & 22.3 \\
\hline
\end{tabular}


Table S2. Spearman correlation coefficients $(\rho)$ between musks under different conditions, and associated p-values with a 0.01 threshold. Values below LOQ were excluded (see "n=" for the number of datapoints $>$ LOQ).

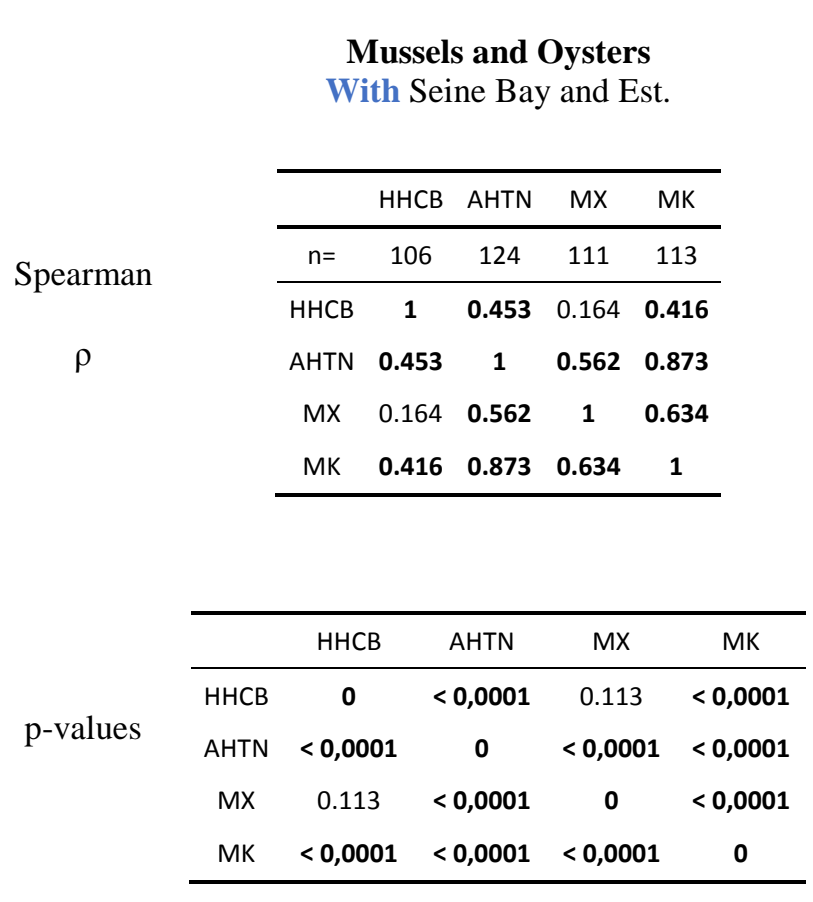
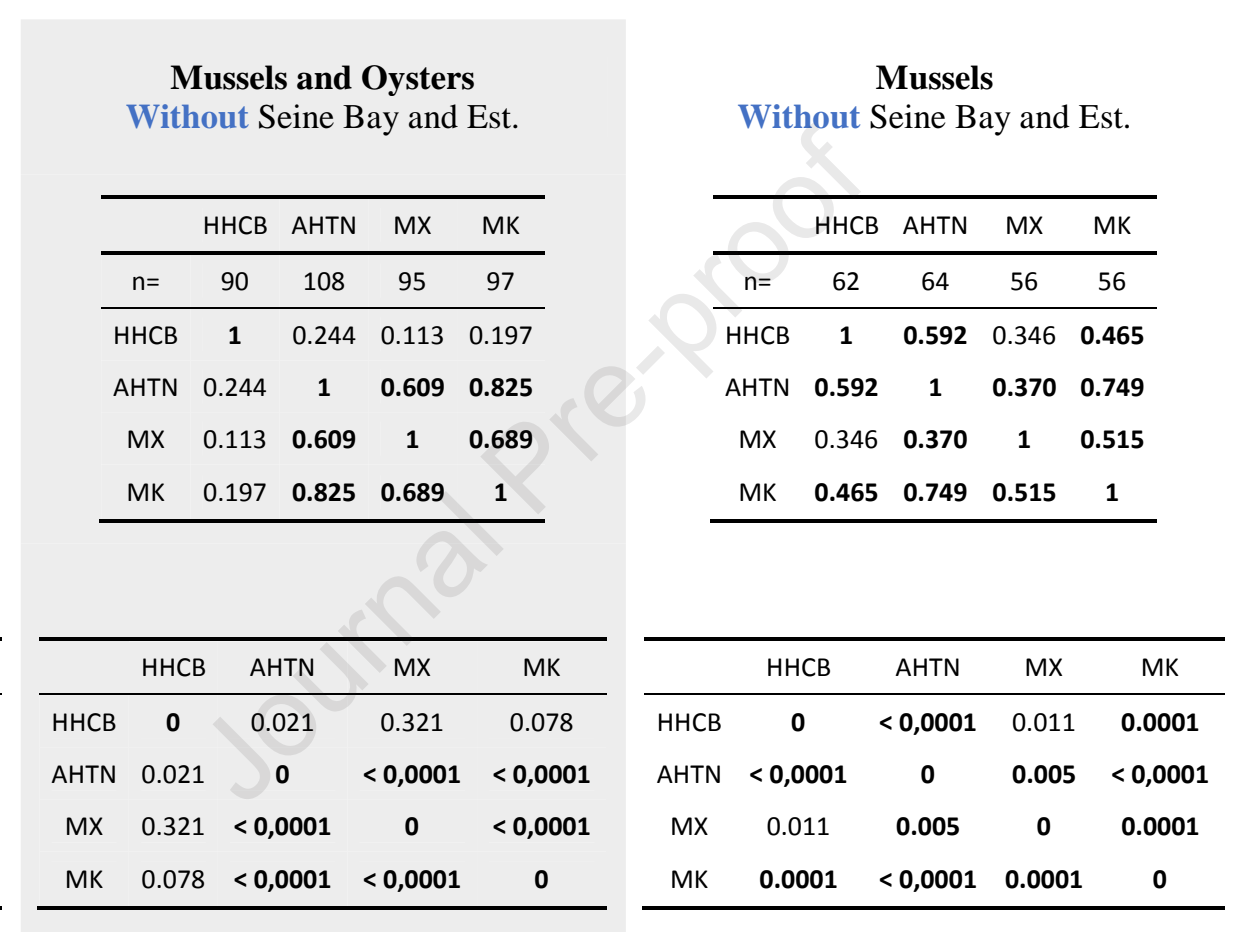

\begin{tabular}{|c|c|c|c|c|}
\hline \multicolumn{5}{|c|}{$\begin{array}{c}\text { Oysters } \\
\text { Without Seine Bay and Est. }\end{array}$} \\
\hline & & $\mathrm{HHCB}$ AHTN & $M X$ & $\mathrm{MK}$ \\
\hline & $n=$ & 44 & 39 & 41 \\
\hline & $\mathrm{HHCB}$ & 0.640 & $0.447 \quad 0$ & 0.535 \\
\hline & AHTN 0. & $.640 \quad 1$ & $0.798 \quad 0$ & 0.881 \\
\hline & $M X \quad 0$. & $.447 \quad 0.798$ & 1 & 0.854 \\
\hline & MK 0. & $\begin{array}{ll}.535 & 0.881\end{array}$ & 0.854 & 1 \\
\hline & $\mathrm{HHCB}$ & AHTN & $M X$ & MK \\
\hline $\mathrm{HHCB}$ & 0 & 0.0003 & 0.026 & 0.005 \\
\hline AHTN & 0.0001 & 0 & $<0,0001$ & $1<0,0001$ \\
\hline$M X$ & 0.026 & $<0,0001$ & 0 & $<0,0001$ \\
\hline MK & 0.005 & $<0,0001$ & $<0,0001$ & 0 \\
\hline
\end{tabular}




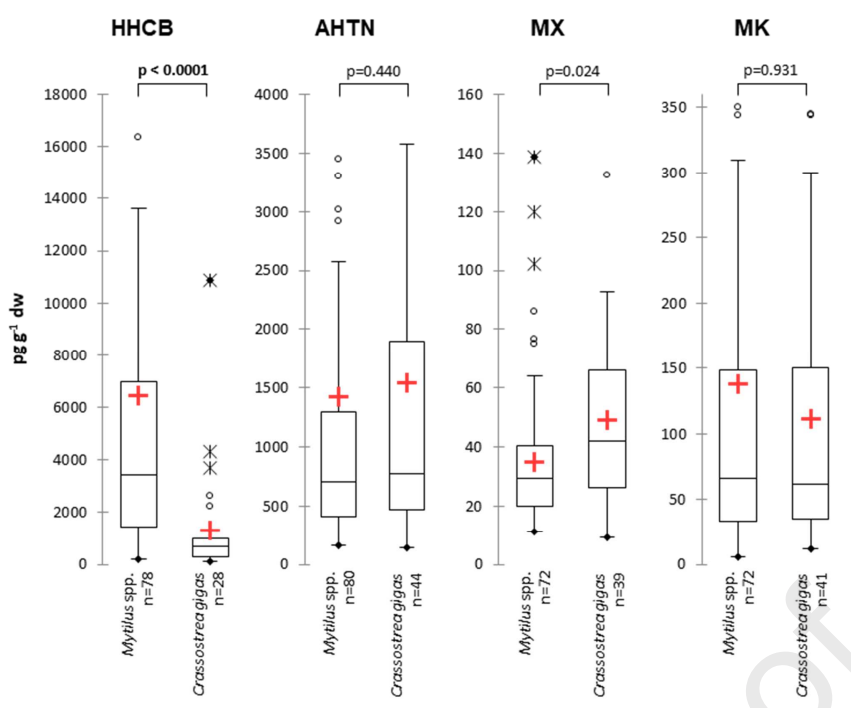

Figure S3. Distribution of the musk concentrations ( $\mathrm{pg} \mathrm{g}^{-1} \mathrm{dw}$ ) in mussels (Mytilus spp.) and oysters (Crassostrea gigas). Statistical differences given for the Mann-Whitney test. Boxes are $1^{\text {st }}$ quartile, median and $3^{\text {rd }}$ quartile, the average is plotted with a red cross and the whiskers indicate min. and max. values excluding outliers. Standard Outliers fall between 1.5*IQR (Inter-Quartile Range) and 3.0*IQR outside of the IQR and are plotted with an open circle, extreme Outliers fall greater than 3.0*IQR outside the IQR and are plotted with an X. 


\section{$1 \quad$ Highlights}

2 - Investigation of synthetic musks in bivalves from French coasts in 2010-2019

3 - Widespread occurrence of HHCB, AHTN, musk xylene and ketone

4 - Species-specific accumulation of HHCB, potentially related to metabolization

$5 \quad-\quad$ Levels reflect urban pressure, notably in the Seine Bay

6 - Significantly decreasing temporal trend for musk xylene only 


\section{Declaration of interests}

$\bigotimes$ The authors declare that they have no known competing financial interests or personal relationships that could have appeared to influence the work reported in this paper.

$\square$ The authors declare the following financial interests/personal relationships which may be considered as potential competing interests: 